\title{
0 Lugar da Informática na Educação Infantil em Documentos Oficiais Brasileiros
}

\section{The Place of The Informatics in Early Childhood Education in Brazilian Official Documents}

\begin{abstract}
Resumo: Considerando que cada vez mais cedo as crianças tem acesso à Informática, antes mesmo do processo de alfabetização, este artigo tem como objetivo problematizar a respeito do que dizem os documentos oficiais norteadores da educação brasileira sobre a Informática na Educação Infantil. Para isso, foram analisados sete documentos do Governo Federal datados de 1996 até 2012. Os resultados apontam que a presença da Informática e seu incentivo são pouco significativos e, geralmente, mencionados à Educação Básica, deixando a Educação Infantil como mera coadjuvante nesta relação. O próprio ProInfo não contempla o nível de ensino em questão e o ProInfância concentra seus investimentos apenas na infraestrutura dos espaços educacionais. Em outros países analisados no artigo, o potencial das Tecnologias da Informação e Comunicação (TICs) e de sua utilização com crianças de 0 a 6 anos já são amplamente reconhecidos. Assim, este artigo revela uma lacuna na realidade brasileira que carece ser suprida.

Palavras-chave: Informática na Educação Infantil. Documentos brasileiros. Políticas de Informática na Educação.
\end{abstract}

\begin{abstract}
Considering that children at a very early age have access to the Informatics, even before the literacy process, this article aims to problematize what the official reference documents of the Brazilian education say about Informatics in Early Childhood Education. To this end, we analyzed seven Federal Government documents dated from 1996 until 2012. The results point out that the presence of Informatics and its incentive is little significant and is often mentioned in relation to Basic Education, leaving the Early Childhood Education play a mere supporting role in this relationship. ProInfo itself does not contemplate this education level and ProInfância concentrates its investments in the infrastructure of these educational spaces. We analyzed that in other countries the potential of the Information and Communication Technologies (TICs) and its use with 0 to 6 year old children have already been broadly recognized. Thus, this article reveals a gap at the Brazilian reality that needs to be fulfilled.
\end{abstract}

Keywords: Informatics in Early Childhood Education. Brazilian documents. Informatics in Education Policies.

CARNEIRO, Ana Carolina Rocha; RAABE, André Luís Alice. O Lugar da Informática na Educação Infantil em Documentos Oficiais Brasileiros. Revista Informática na Educação: teoria e prática, Porto Alegre, v. 18, n. 1, p. 51-66, jan./jun. 2015.

\author{
Ana Carolina Rocha Carneiro \\ André Luís Alice Raabe \\ Universidade do Vale do Itajaí
}

\section{Introdução}

A presença da Informática na Educação já não é mais novidade. Segundo Valente (1999), o uso do computador na educação no Brasil "[...] teve início com algumas experiências em universidades, no princípio da década de $70[\ldots]^{\prime \prime}$ (VALENTE, 1999, p. 13). O autor relata, ainda, que a introdução da Informática na Rede Pública de Educação no país foi e é norteada pela transformação do paradigma pedagógico, quando, a partir de 1982, as políticas públicas relacionadas à informática começaram a ser planejadas (VALENTE, 1999).

Essas políticas, como o Programa Nacional de Tecnologia Educacional (ProInfo) de 1997, trouxeram mudanças para a linha do tempo que indica a presença da Informática na Educação. A partir desse panorama, este artigo vale-se 
de um dos aforismos de Papert (1994, p. 10): "Por que, durante um período em que tantas atividades humanas foram revolucionadas, não vimos mudanças comparáveis na forma como ajudamos nossas crianças a aprender?".

O autor descrevia um cenário em constante transformação que, quase duas décadas mais tarde, tornar-se-ia fato: "[...] ao redor do mundo inteiro, as crianças entraram em um apaixonante e duradouro caso de amor com os computadores" (PAPERT, 1994, p. 7). Não é incomum observarmos crianças, provavelmente cada vez mais novas do que aquelas que $\mathrm{Pa}-$ pert mencionava em seus textos, em contato contínuo e diário com as tecnologias em suas variadas formas. Elas podem facilmente serem retratadas na atualidade por meio do que descreve o autor:

[...] o caso de amor envolve mais que o desejo de fazer coisas com os computadores. Ele também apresenta um elemento de possessividade e, mais importante, de afirmação de identidade intelectual. Grande número de crianças vê o computador como 'nosso' como algo que pertence a elas, à sua geração. Muitas observam que se sentem mais confortáveis com as máquinas do que seus pais e professores. Elas aprendem a usá-las mais fácil e naturalmente. No momento, alguns de nós, da velha guarda, podemos ter adquirido, de algum modo, o conhecimento especial que nos permite dominar o computador, mas as crianças sabem que é apenas uma questão de tempo até que elas herdem as máquinas. Elas são a geração da Informática (PAPERT, 1994, p. 7, grifos do autor).

Esse retrato é reforçado por Passerino (2001), quando ressalta que não se pode esquecer de que hoje as crianças estão saturadas de tecnologia em seu cotidiano e esperam poder utilizá-la na escola como parceira de aprendizagem junto ao professor. Os ambien- tes educacionais que recebem essas crianças, seguindo essa visão, precisam acompanhar as demandas pedagógicas que surgiram com essas inovações.

A análise aqui proposta traz à tona um nível de ensino que parece ainda não se encaixar neste novo velho contexto da Informática na Educação: a Educação Infantil. O objetivo é problematizar a respeito do que dizem os documentos oficiais norteadores da educação brasileira sobre a Informática na Educação Infantil. Existem diretrizes nestes documentos para o uso das Tecnologias da Informação e Comunicação (TICs) junto a este nível de ensino? O intuito é, de a partir destas constatações, se fomentar as discussões da relação da Educação Infantil com a tecnologia.

Para isso, foram selecionados sete documentos oficiais do Governo Federal que norteiam a educação brasileira, sendo eles a Lei de Diretrizes e Bases (LDB) de 1996, o Referencial Curricular Nacional para a Educação Infantil de 1998, as Diretrizes Curriculares Nacionais para a Educação Infantil de 2010, o Projeto de Lei que aprova o Plano Nacional de Educação (PNE) para o decênio 2011-2020 e o Manual de Orientação Pedagógica Brinquedos e Brincadeiras de Creches de 2012. Além desses, textos como a nova Lei de no 12.796 , de 4 de abril de 2013 - que altera a LDB de 1996 -, os Indicadores de Qualidade na Educação Infantil e o Guia de Tecnologias Educacionais de 2009, do Ministério da Educação (MEC), serviram, também, de subsídio para a análise.

Documentos que apontam diretrizes ou orientações para a prática da Educação Infantil foi o critério utilizado para a seleção do material deste artigo, uma vez que não existem documentos com foco exclusivo sobre a Informática para esse nível de ensino, pelo menos em nosso país. Importante ressaltar que se optou 
por não selecionar nenhum material estadual ou municipal para o escopo do artigo, visto que cada região contempla diferentes aspectos e características que promoveriam diferentes análises. Problematizou-se sobre a macro estrutura do tema Informática na Educação Infantil de maneira a proporcionar contribuições para estudos que foquem em suas micro estruturas. Além disso, é preciso considerar que estes documentos marcam épocas distintas na construção da política/história educacional do país, tendo a participação de diferentes grupos com diferentes prioridades.

Por meio da leitura do material selecionado, realizou-se uma busca por palavras-chave que denotam o tema aqui problematizado para a identificação e o destaque do quê se prevê ou se sugere, teoricamente, quanto ao lugar da Informática na Educação Infantil nesses documentos. Termos como informática, tecnologia, computador, internet, software, mídia, TICs e televisão foram pesquisados.

Na próxima seção, será relembrada a definição da Educação Infantil, tendo, como pano de fundo, relatos de utilização e discussão sobre Informática nesse nível de ensino em outros países, para, depois, ser feita a análise geral dos documentos oficiais brasileiros. Este texto segue descrevendo, ainda, dois programas do Governo Federal - o ProInfo e o Programa Nacional de Reestruturação e Aquisição de Equipamentos para a Rede Escolar Pública de Educação Infantil (ProInfância) - que tem o intuito de equipar a educação no país.

\section{Informática na Educação Infantil}

A Constituição de 1988 reconhece a Educação Infantil como um dever do Estado para a educação, sendo o atendimento em creches e pré-escolas um direito social das crianças
(BRASIL, 1988). Essa conquista resultou de um processo com ampla participação dos movimentos comunitários, de mulheres, de trabalhadores, dos próprios profissionais da educação e movimentos de redemocratização do país (BRASIL, 2010).

Esse nível de ensino deve ter garantida sua oferta "[...] pública, gratuita e de qualidade, sem requisito de seleção [...]" (BRASIL, 2010, p. 12). Além disso, a Educação Infantil é a primeira etapa da educação básica

[...] oferecida em creches e pré-escolas, às quais se caracterizam como espaços institucionais não domésticos que constituem estabelecimentos educacionais públicos ou privados que educam e cuidam de crianças de 0 a 5 anos de idade no período diurno, em jornada integral ou parcial, regulados e supervisionados por órgão competente do sistema de ensino e submetidos a controle social (BRASIL, 2010, p. 12).

Como parte da Educação Básica, é indispensável que se concentrem esforços para o desenvolvimento desse nível de ensino com qualidade, fomentando discussões que coloquem a Educação Infantil frente às transformações da sociedade, afinal esse é o primeiro passo que o aluno dá na sua trajetória escolar. Contudo, pensar sobre a Informática na Educação Infantil, "[...] não se trata de usar ou não um recurso técnico determinado dentro da sala de aula, se trata de abrir a porta para deixar o mundo entrar, contextualizar a educação dentro da sociedade, para que esta, dialeticamente, afete e seja afetada pela educação" (PASSERINO, 2001, p. 181).

Ainda mais para um nível de ensino com frequentes debates contemporâneos sobre sua responsabilidade/função social e composição, na qual, o currículo, a formação de professores, o próprio sujeito da Educação Infantil (Crian- 
ça? Aluno?), as propostas pedagógicas e eixos de saberes e conhecimento rendem objetos de diversos estudos. Dois dos elementos articuladores destes eixos, por exemplo, a brincadeira e a interação (BRASIL, 2010b, p. 25), podem vislumbrar a Informática como um alicerce, não como meio de salvação e sim como tecnologias para comunicação e a cultura:

[...] a resposta não será enfeitar os materiais de ensino com penduricalhos - dar mais vida ao currículo com um brilho superficial da cultura digital amiguinha das crianças. Nem será adotar a tecnologia digital a serviço de formas estritamente instrumentais de aprendizagem, numa tentativa de torná-la mais agradável (BUCKINGHAM, 2010, p. 47).

É o que Valente (1993, p. 1-2) retrata ser um paradigma construcionista, em que a "[...] ênfase está na aprendizagem ao invés de estar no ensino; na construção do conhecimento e não na instrução". Neste sentido, a Informática ou as TICs apresentam potencial para incentivar a "[...] curiosidade, a exploração, o encantamento, o questionamento, a indagação e o conhecimento das crianças em relação ao mundo físico e social, ao tempo e à natureza" (BRASIL, 2010b, p. 26), uma das experiências que devem ser garantidas no currículos das práticas pedagógicas da Educação Infantil.

A discussão sobre Informática na Educação Infantil já está presente em outros países. É o que demonstra uma pesquisa analítica do Instituto para Tecnologias da Informação na Educação, da Organização das Nações Unidas (UNESCO), na qual se ressalta o reconhecimento do potencial das TICs para crianças entre três e sete anos.

Nessa pesquisa, há, como contribuição, relatos de nove países. Mesmo reconhecendo que uma das dificuldades desse processo é a acessibilidade a esses recursos tecnológicos, para centrar a convicção sobre o tema, foi utilizada a fala de um professor de um Centro de Educação Infantil de uma das regiões mais pobres do sul do Chile, onde todas as crianças pertencem à comunidade indígena Mapuche:

Nós acreditamos no poder das TICs para motivar e desafiar as crianças, expandir suas percepções de mundo, sua linguagem e pensamento, e desenvolver seus valores como sendo indígenas. Nós vemos as TICs como um componente importante para o processo de aprendizagem atual, particularmente assim em ambientes pobres (KALAS, 2010, p. 9 , tradução nossa).

No documento, são descritas iniciativas de uso das TICs por 17 diferentes Centros de Educação Infantil, como a utilização de emails, brinquedos programáveis como robôs, softwares educacionais, quadros interativos, entre outros. Também, são delineadas as áreas da aprendizagem que podem ter na utilização das TICs um suporte para o desenvolvimento, desde cedo, das crianças, como a comunicação e a colaboração, a criatividade, o jogo de dramatização e o aprender a aprender. Além dessas, outras áreas do conhecimento que podem ser aprimoradas pela integração das TICs também são descritas: aprendizagem de música, educação midiática, alfabetização, compreensão matemática, ciência, resolução de problemas, entre outros (KALAS, 2010).

Outro texto que relata "[...] evidências do potencial da tecnologia como apoio ao desenvolvimento da política e prática educacional" (AUBREY; DAHL, 2008, p. 3, tradução nossa) para crianças abaixo de cinco anos foi desenvolvido pela Universidade de Warwick, no Reino Unido. O estudo de Aubrey e Dahl (2008) revisou softwares e hardwares disponíveis para essas crianças, o cenário atual da utilização de TICs pelas crianças em casa e na escola, 
o conjunto de habilidades e de conhecimentos dos professores que atendem essas crianças, a contribuição da tecnologia para o aprendizado e o desenvolvimento dessas crianças, os riscos associados a essa utilização, quais conselhos os pais e os professores precisam para utilizar a tecnologia e onde esses conselhos estão disponíveis hoje.

Quanto à contribuição da tecnologia para o desenvolvimento e aprendizagem das crianças, no documento são apontadas três grandes áreas:

- O desenvolvimento de disposições para o aprendizado que perpassam pelo desenvolvimento pessoal, social e emocional, e através dos primeiros anos da educação em geral.

- O conhecimento e entendimento do mundo no sentido mais amplo da comunicação, linguagem e alfabetização, resolução de problemas, raciocínio e matemática, desenvolvimento de criatividade e comportamento lúdico e de lazer;

- A aquisição de habilidades operacionais. (AUBREY; DAHL, 2008, p. 5, tradução nossa).

Experiências de outros países como a da Universidade Comenius, da Eslováquia, apontam "[...] a robótica ou os brinquedos programáveis como uma nova dimensão para atividades no chamado jardim de infância" (JANKA, 2008 , p. 1, tradução nossa). Janka (2008, p. 2, tradução nossa) descreve que, dentre outros aspectos, "[...] as atividades com tecnologias de controle podem ajudar as crianças a desenvolverem mais habilidades gerais de pensar e aprender, e os brinquedos programáveis podem simular resoluções de problemas em condições reais do ambiente da própria criança".
O Guia para desenvolvimento de um currículo com TICs na Educação Infantil britânica também aponta como essas tecnologias contribuem na aprendizagem das crianças "[...] por meio da identificação de áreas chave como, comunicação e colaboração, criatividade, jogo sócio-dramático e o aprender a aprender" (SIRAJ-BLATCHFORD, I.; SIRAJ-BLATCHFORD, J., 2006, p. 9, tradução nossa).

Contudo, uma publicação da Alliance for Childhood, organização do estado de Maryland, nos Estados Unidos (CORDES; MILER, 2000), aponta uma série de argumentos que demonstram os riscos da utilização de computadores na infância. Os perigos dessa relação, segundo Cordes e Miler (2000), são elencados por meio da saúde física das crianças, seus desenvolvimentos social, emocional, intelectual, moral e criativo, como:

- lesões muscoesqueléticas;

- problemas de visão;

- falta de exercícios e obesidade;

- emissões tóxicas e radiação eletromagnética;

- vidas isoladas;

- saber centrado no computador;

- pouca automotivação;

- distanciamento da comunidade;

- comercialização da infância;

- imaginação atrofiada;

- perda do pensamento abstrato;

- linguagem e alfabetização debilitadas;

- pouca concentração;

- pouca paciência para trabalhos difíceis;

- plágio;

- distração do significado (CORDES; MILLER, 2000, p. 19-33, tradução nossa).

Essa é apenas uma pequena fração das produções científicas e documentais sobre a temática encontrada em demais países. Dagan, 
Kuperman e Mioduser (2012) também retratam a realidade da Informática na Educação Infantil fora do Brasil, quando relatam "[...] o primeiro estágio de implementação de um currículo inovador para o pensamento tecnológico no jardim de infância ${ }^{1}$ em Israel" (DAGAN; KUPERMAN; MIODUSER, 2012, p. 1, tradução nossa).

No Brasil algumas iniciativas do uso de Informática na Educação Infantil também podem ser encontradas. Elas reforçam a necessidade de se fomentar a discussão desta prática, já que por ainda não existir uma cultura de utilização de tecnologia neste nível de ensino no país, são poucas as reflexões a esse respeito e Ihes faltam aporte teórico como fundamento para as experiências descritas, sem um contraste profundo com abordagens teóricas da utilização de computadores para as crianças com idade entre zero e cinco anos.

Schlickmann et al. (2006), Mousquer e Ro$\lim$ (2011), Joana Piske (2000), Lima (2002), Tavares et al. (2007), Mattei (2003), Rosa (2010), e Jesus, Uriarte e Raabe (2010) são alguns exemplos destas iniciativas. Os três últimos mencionam, respectivamente: uma experiência em Blumenau (SC) com alunos com idade entre cinco e seis anos na construção de um software educacional de miscigenação de cores, no qual elas sugeriram mudanças nos ícones do software com seus próprios desenhos; outra experiência com alunos da Educação Infantil, em Manaus, realizada com softwares educacionais de desenhos e pinturas, revelou que o uso do computador como recurso pedagógico proporcionou o desenvolvimento da criatividade do aluno, o estímulo ao pensamento e à autonomia da criança, entre

\footnotetext{
1 "Considerando-se o foco do estudo crianças de 5 e 6 anos [...]" (DAGAN; KUPERMAN; MIODUSER, 2012, p. 1, tradução nossa).
}

outros aspectos; e a utilização do objeto de aprendizagem Zorelha com crianças a partir de quatro anos em Santa Catarina, voltado para a Educação Musical Infantil, que demonstrou potencial como ferramenta para a construção de conhecimento musical sob a forma de brincadeiras baseadas em explorações sonoras.

A seção que segue apresenta a análise do contexto brasileiro, de acordo com os documentos oficiais.

\section{Análise dos Documentos Oficiais Brasileiros}

Partindo do documento norteador mais antigo da educação e da legislação ainda em uso no país, a LDB de 1996 reconhece a Educação Infantil como nível escolar da Educação Básica, sendo aquela a sua primeira etapa. Segundo o artigo 29 da LDB, a Educação Infantil "[...] tem finalidade o desenvolvimento integral da criança de até 6 (seis) anos, em seus aspectos físico, psicológico, intelectual e social, complementando a ação da família e da comunidade" (BRASIL, 1996) ${ }^{2}$.

Quanto à Informática, ela não consta como um elemento da Educação Infantil no documento - considerando a utilização do computador, por exemplo, "[...] no processo de aprendizagem dos conteúdos curriculares de todos os níveis e modalidades de educação" como menciona Valente (1997, p. 1). Esse campo é apresentado quando mencionada a Educação Básica - que tem como primeira etapa a Educação Infantil -, e, de maneira mais

\footnotetext{
${ }^{2}$ Considerando a recente aprovação da Lei no 12.796 , de 4 de abril de 2013, que altera a LDB de 1996 e "estabelece a obrigatoriedade da matrícula das crianças com quatro anos na pré-escola" (BRASIL, 2013) e a consequente migração das crianças de 6 anos para o primeiro ano do Ensino Fundamental de 9 anos.
} 
significativa, nas implicações dos ensinos Fundamental e Médio. Sua presença é descrita por meio da formação com vistas à compreensão da tecnologia e dos conhecimentos científico-tecnológicos, e o destaque para a educação tecnológica básica no currículo.

\section{Seção III - Do Ensino Fundamental}

[...] II - a compreensão do ambiente natural e social, do sistema político, da tecnologia, das artes e dos valores em que se fundamenta a sociedade;

\section{Seção IV - Do Ensino Médio}

[...] IV - a compreensão dos fundamentos científico-tecnológicos dos processos produtivos, relacionando a teoria com a prática, no ensino de cada disciplina.

[...] Art. 36. O currículo do ensino médio observará o disposto na Seção I deste Capítulo e as seguintes diretrizes:

I - destacará a educação tecnológica básica, a compreensão do significado da ciência, das letras e das artes; o processo histórico de transformação da sociedade e da cultura; a língua portuguesa como instrumento de comunicação, acesso ao conhecimento e exercício da cidadania;

[...] \$ 10. Os conteúdos, as metodologias e as formas de avaliação serão organizados de tal forma que ao final do ensino médio o educando demonstre:

I - domínio dos princípios científicos e tecnológicos que presidem a produção moderna [...] (BRASIL, 1996).

Importante ressaltar que a Lei de Diretrizes e Bases de 1996 prevê para o Ensino Médio a adoção de "[...] metodologias de ensino e de avaliação que estimulem a iniciativa dos estudantes" (BRASIL, 1996). Com algumas das perspectivas já apresentadas do cenário da Informática na Educação e a relação desta com as crianças, não é possível almejar estímulos para os alunos da Educação Infantil? A grande variedade de softwares educacionais existente hoje não daria conta de encantar as crianças em relação à aprendizagem e ao ensino?

Outro documento oficial do Governo Federal, o Referencial Curricular Nacional para a Educação Infantil, de 1998, dividido em três volumes,

[...] foi concebido de maneira a servir como um guia de reflexão de cunho educacional sobre objetivos, conteúdos e orientações didáticas para os profissionais que atuam diretamente com crianças de zero a seis anos, respeitando seus estilos pedagógicos e a diversidade cultural brasileira (BRASIL, 1998a, p. 7).

Os dois primeiros volumes não fazem alusão ao tema aqui em análise. Já o terceiro, denominado Conhecimento de Mundo, que discorre sobre a construção das diferentes linguagens pelas crianças e as relações que estabelecem com os objetos de conhecimento, traz a sugestão de que

[...] materiais e instrumentos, como mimeógrafos, vídeos, projetores de slides, retroprojetores, mesas de luz, computadores, fotografias, xerox, filmadoras, CD-ROM etc., possibilitam o uso da tecnologia atual na produção artística, o que enriquece a quantidade de recursos de que o professor pode lançar mão (BRASIL, 1998b, p. 112).

Além disso, na indicação de recursos didáticos e sua utilização, o documento relata que "[...] o trabalho com a escrita pode ser enriquecido por meio da utilização do computador" (BRASIL, 1998b, p. 156). Aliás, sua contribuição mais significativa, a apresentação mais explícita do lugar da Informática na Educação Infantil, é encontrada logo em seguida, quando se expõe que 
[...] ainda são poucas as instituições infantis que utilizam computadores na sua prática, mas esse recurso, quando possível, oferece oportunidades para que as crianças tenham acesso ao manuseio da máquina, ao uso do teclado, a programas simples de edição de texto, sempre com a ajuda do professor (BRASIL, 1998b, p. 156).

O reconhecimento de oportunidades que a Informática pode trazer para esse nível de ensino, não identificado nas documentações que Ihe sucederam, é ponto de partida para pensar-se em mudanças para a Educação Infantil, no sentido de atualizá-la e adaptá-la diante das frequentes transformações que estas crianças já apresentam na atualidade. Villardi e Oliveira corroboram esse fato quando dizem que "[...] o computador está presente na vida da criança da modernidade e afeta ativamente a construção de sua identidade" (VILLARDI; OLIVEIRA, 2005, p. 30).

Em consenso com o último documento, as Diretrizes Curriculares Nacionais para a Educação Infantil de 2010, fixadas pela Resolução no 5 de 17 de dezembro de 2009 (BRASIL, 2010a), apesar de não abordarem o tema aqui analisado, destacam no capítulo Práticas Pedagógicas da Educação Infantil a utilização de materiais que possam enriquecer os recursos para o professor. $\mathrm{O}$ documento tem por objetivo estabelecer as diretrizes a serem observadas na organização de propostas pedagógicas na Educação Infantil as quais foram produzidas em articulação com o documento de diretrizes da Educação Básica. Além disso, "[...] reúnem princípios, fundamentos e procedimentos [...] para orientar as políticas públicas e a elaboração, planejamento, execução e avaliação de propostas pedagógicas e curriculares de Educação Infantil" (BRASIL, 2010a, p. 11).

A menção à Informática na Educação Infantil, nessas diretrizes, dá-se nos eixos do currí- culo, cujas práticas devem ter como norteadoras as interações e a brincadeira, de forma a garantir experiências que "[...] possibilitem a utilização de gravadores, projetores, computadores, máquinas fotográficas, e outros recursos tecnológicos e midiáticos" (BRASIL, 2010a, p. 27).

Já os Indicadores de Qualidade na Educação Infantil de 2009 não apresentam o uso de computadores ou demais recursos de Informática voltados às crianças, limitando-se a direcioná- los para a elaboração da proposta pedagógica por parte da equipe da instituição de Educação Infantil, que deve estar atualizada quanto às orientações legais vigentes e os conhecimentos a respeito desse nível de ensino. É indicado que "[...] materiais acessíveis pela internet, entre outros recursos, são importantes subsídios para fundamentar o planejamento do trabalho pedagógico, a formação em serviço e o relacionamento com as famílias" (BRASIL, 2009, p. 37).

O objetivo desses indicadores é "[...] auxiliar as equipes que atuam na educação infantil, juntamente com famílias e pessoas da comunidade, a participar de processos de autoavaliação da qualidade de creches e pré-escolas que tenham um potencial transformador" (BRASIL, 2009 , p. 14). Se as oportunidades já reconhecidas pelo Referencial Curricular Nacional para a Educação Infantil em 1998 tivessem sido exploradas a ponto de impactar na prática das creches e pré-escolas do país, um documento que pretende avaliar a qualidade dessa educação não teria em uma de suas dimensões para avaliação as experiências com a Informática? Essa seria uma ocasião para, inclusive, aferir ou não o lugar desse campo nesse ambiente educacional.

Quanto ao Projeto de Lei que aprova o PNE para o decênio 2011-2020, os princípios fundamentais para a Educação Infantil concen- 
tram-se em expandir a matrícula nas creches, universalizar o atendimento e ampliar a oferta. Apesar de uma de suas dez diretrizes ser a "[...] promoção humanística, científica e tecnológica do país" (BRASIL, 2010b, p. 1), não há menção sobre a Informática na Educação Infantil.

O documento limita-se a explorar tal área para outros níveis de ensino da Educação Básica, da qual novamente ressaltamos a participação da Educação Infantil. Algumas de suas estratégias previstas que talvez poderiam vislumbrar a questão da Informática na Educação Infantil no documento são:

2.11) Universalizar o acesso à rede mundial de computadores em banda larga de alta velocidade e aumentar a relação computadores/estudante nas escolas da rede pública de educação básica, promovendo a utilização pedagógica das tecnologias da informação e da comunicação.

[...]

[...] selecionar, certificar e divulgar tecnologias educacionais para alfabetização de crianças, assegurada a diversidade de métodos e propostas pedagógicas, bem como o acompanhamento dos resultados nos sistemas de ensino em que forem aplicadas.

Manter e aprofundar programa nacional de reestruturação e aquisição de equipamentos para a rede escolar pública de educação infantil, voltado à expansão e à melhoria da rede física de creches e pré-escolas públicas. [...] estimular a articulação entre programas de pós-graduação stricto sensu e cursos de formação de professores para a educação infantil, de modo a garantir a construção de currículos capazes de incorporar os avanços das ciências no atendimento da população de 4 e 5 anos. (BRASIL, 2010b, p. 4, 5 e 7)

Tal qual os demais documentos, mais uma vez é possível notar que a preocupação registrada foca-se em garantir a infraestrutura, cer- tamente necessária, a esses ambientes educacionais, sem fazer-se alusão a efetivas ações que promovam experiências voltadas à aprendizagem e ao desenvolvimento de habilidades - iniciativas estas que poderiam ser subsidiadas por meio da Informática, assim como o são para os demais níveis de ensino. Podemos perceber, também, o progresso estagnado quanto ao reconhecimento caracterizado no Referencial Curricular da Educação Infantil de 1998.

Já o Manual de Orientação Pedagógica Brinquedos e Brincadeiras de Creches, de 2012, reúne, em seu primeiro módulo, Brincadeiras e interações nas Diretrizes Curriculares para a Educação Infantil, um tópico especial para Brincadeiras e tecnologia. O documento tem a finalidade de orientar a seleção, a organização e o uso de brinquedos e brincadeiras nas creches, com base nas Diretrizes Curriculares Nacionais para a Educação Infantil.

Antes de apresentar seis sugestões sobre o aproveitamento adequado da tecnologia nas brincadeiras infantis, no documento, é descrito que "[...] na creche, a tecnologia está presente em forma de brinquedos como fogão, geladeira, ou meios de comunicação como o karaokê e o celular, que servem para as brincadeiras de imitação" (BRASIL, 2012, p. 53). A primeira das sugestões talvez seja a mais expressiva relacionada à utilização da tecnologia: "Com o apoio da professora, as crianças podem pesquisar temas de interesse na internet, escanear, gravar e imprimir desenhos realizados em outras atividades, tendo o computador como suporte para aprofundar o conhecimento" (BRASIL, 2012, p. 54).

As demais sugestões remetem: à gravação de filmes para as crianças assistirem - o que "[...] contribui para o desenvolvimento da memória [...]" (BRASIL, 2012, p. 54) -, e para as professoras assistirem aos programas que 
as crianças gostam junto a elas de maneira a comentá-lo e avaliá-lo junto às crianças - o que "[...] colabora para uma visão crítica dos meios de comunicação [...]" (BRASIL, 2012, p. 54) -; aos brinquedos que fazem com que as crianças imitem o mundo adulto utilizando celulares, rádio, máquinas fotográficas ou televisão (BRASIL, 2012); a deixar que as crianças fotografem para que, por meio dessa experiência, seus interesses sejam descobertos ou para que crianças maiores construam uma máquina fotográfica com a ajuda dos adultos (BRASIL, 2012); à utilização de brinquedos que produzem sons e movimentos quando acionados por botões, mas que exigem "[...] a necessidade de reposição de pilhas $[. .$.$] , constante super-$ visão do adulto [...] e a necessidade de separar o lixo eletrônico" (BRASIL, 2012, p. 54). Esse documento é o único a mencionar algo semelhante à utilização de brinquedos programáveis ou mesmo robôs na Educação Infantil, como mencionado no documento da UNESCO em outros países. De qualquer forma, é pouca a orientação pedagógica relativa ao uso da internet para pesquisas, por exemplo.

O Guia de Tecnologias Educacionais de 2009, do MEC, que "[...] busca oferecer aos sistemas de ensino uma ferramenta a mais que os auxilie na decisão sobre a aquisição de materiais e tecnologias para uso nas escolas brasileiras de educação básica pública" (ANDRÉ, 2009, p. 13), é o último documento desta análise. Esse texto, o qual poderia promover as sugestões de experiências voltadas à Informática que não foram encontradas nos demais documentos, também se limita em deixar a Educação Infantil como mera coadjuvante nessa relação. Suas ações e seus programas são referenciados à Educação Básica, com o foco, novamente, sob os ensinos Fundamental e Médio. São previstos dois portais educacio- nais (Portal dos Professores da UFSCar e Portal Estuda Mais Brasil) voltados a difundir conteúdos e ferramentas interativas e o Programa de Gestão Educacional.

Na categoria Ensino Aprendizagem, três outras ações são sugeridas para a Educação Básica (Aprender Fazendo, Método das Boquinhas e Tabulinha). A primeira constitui-se em uma metodologia de resolução de problemas para o desenvolvimento de aprendizagens formais no contexto escolar, a segunda utiliza livros com o objetivo de trabalhar aquisição da leitura e escrita com crianças de 4 a 6 anos e a terceira voltada ao ensino e aprendizagem de conceitos de geometria plana por meio de um software que permite a construção virtual de objetos geométricos (ANDRÉ, 2009).

A Educação Básica ainda compreende outras quatro ações da categoria Formação dos Profissionais da Educação (CECEMCA/UNESP: Tecnologia Educacional na Formação Continuada de Professores, EaD - TIC, Mesa Educacional Alfabeto Educação Especial e Tonomundo). Elas reúnem ações dirigidas à formação continuada de professores e à produção de material didático (ANDRÉ, 2009); um programa de formação continuada com ferramentas de educação à distância (ANDRÉ, 2009); uma combinação de software educacional e elementos de hardware para a construção da linguagem e aprendizagem de LIBRAS e braile, em nível de alfabetização na Educação Infantil (ANDRÉ, 2009); e por último, um programa de formação continuada para o uso da informática educativa para além do laboratório, do qual algumas escolas já ampliaram sua metodologia para a Educação Infantil (ANDRÉ, 2009).

Não muito distante dos demais documentos analisados, o Guia limita-se a propor ações principalmente voltadas à formação continuada dos professores, enquanto que alguns do- 
cumentos retêm seus esforços na infraestrutura das creches e pré-escolas.

Já que a recente aprovação da Lei no 12.796, de 4 de abril de 2013 - que altera a LDB de 1996 - estabelece a obrigatoriedade da matrícula das crianças com quatro anos na pré-escola, é preciso pensar na qualidade do ensino atribuído a essa nova etapa obrigatória, da qual a organização depende de avaliação mediante acompanhamento e registro do desenvolvimento das crianças e expedição de documentação que permita atestar os processos de desenvolvimento e aprendizagem delas (BRASIL, 2013). A Informática, então, poderia ser inserida nesse contexto como um estímulo a mais para a evolução desses processos, se discutida e planejada de maneira eficaz.

\subsection{O ProInfo e o ProInfância}

Quanto ao aspecto da infraestrutura das escolas de Educação Básica do país, dois são os programas do Governo Federal responsáveis. Eles fazem parte do Fundo Nacional de Desenvolvimento da Educação (FNDE), uma autarquia federal criada pela Lei no 5.537, de 21 de novembro de 1968, e alterada pelo Decreto-Lei no 872, de 15 de setembro de 1969 que é responsável pela execução de políticas educacionais do $\mathrm{MEC}^{3}$.

O ProInfo é um programa educacional criado pela Portaria no 522, de 9 de abril de 1997, pelo MEC, para promover o uso da tecnologia como ferramenta de enriquecimento pedagógico no ensino público fundamental e médio. Inicialmente, foi denominado de Programa Nacional de Informática na Educação e, a partir de dezembro de 2007, mediante a criação do

\footnotetext{
3 Mais informações no site do FNDE, disponível em: <http:// www.fnde.gov.br/fnde/institucional/quem-somos> Acesso em: 11 fev. 2014
}

decreto $n^{\circ}$ 6.300, passou a ter o nome que leva hoje, tendo como principal objetivo promover o uso pedagógico das tecnologias de informação e comunicação nas redes públicas de educação básica. Seu funcionamento dá-se de forma descentralizada, por meio de Coordenações Estaduais e dos Núcleos de Tecnologia Educacional (NTEs), dotados de infraestrutura de informática e comunicação que reúnem educadores e especialistas em tecnologia de hardware e software 4 .

O documento que orienta a adesão das prefeituras ao programa especifica que, para serem beneficiadas com equipamentos como laboratórios de informática, computadores interativos ou lousas digitais, as escolas devem obedecer a critérios, sendo um deles escolas que não sejam exclusivamente de educação infantil (creche e pré-escola) ${ }^{5}$.

Já o ProInfância foi instituído pela Resolução no 6, de 24 de abril de 2007, e é parte das ações do Plano de Desenvolvimento da Educação (PDE) do MEC. Seu principal objetivo é prestar assistência financeira ao Distrito Federal e aos municípios visando garantir o acesso de crianças a creches e a escolas de Educação Infantil da rede pública.

Para aderir ao programa, as prefeituras devem enviar projetos solicitando o tipo de construção a qual desejam ser contempladas. Nesse projeto, solicita-se que seja especificado se são previstos espaços para o desenvolvimento de atividades diferenciadas (como brincadeiras, jogos, biblioteca, brinquedoteca, informática e outros) $)^{6}$.

\footnotetext{
${ }^{4}$ Mais informações no site do ProInfo, disponível em: <http:// www.fnde.gov.br/programas/programa-nacional-de-tecnologia-educacional-proinfo/proinfo-apresentacao> Acesso em: 9 fev. 2014.

5 Mais informações no site do ProInfo, disponível em: <https://www.fnde.gov.br/sigetec/upload/manuais/sigetec_adesao_prefeituras.pdf> Acesso em: 8 jun. 2015.

6 Mais informações no site do ProInfância, disponível em: <http://www.fnde.gov.br/programas/proinfancia/proinfancia-
} 
Mais uma vez, percebe-se a falta de força de ações que remetam à Informática na Educação Infantil. Tanto documentos quanto programas não pensam em inovar o espaço educacional para as crianças das creches e pré-escolas. 0 enfoque dá-se no pessoal e no material, mesmo não havendo menção a computadores. Se a formação continuada é descrita, a prática pedagógica não o é.

O tema deste artigo, a Informática na Educação Infantil, nos registros analisados, não é significativo se levarmos em consideração a definição de Valente (1993) para os quatro ingredientes básicos necessários para a implantação do computador na educação: "[...] o computador, o software educativo, o professor capacitado para usar o computador como meio educacional e o aluno [...]" (VALENTE, 1993, p. 1). Parece que, quanto ao Governo Federal, nenhuma dessas vertentes direciona-se expressivamente à Educação Infantil.

O autor ainda destaca que não é apenas a compra dos equipamentos que solucionará a situação. Na verdade, faz-se necessária uma mudança pedagógica e desafiadora, a qual, se não for realizada, fará com que os professores tenham que se contentar em trabalhar em um ambiente obsoleto, fora do contexto da atual sociedade (VALENTE, 1999). Ainda, para o pesquisador:

Se quisermos que a Informática na Educação ultrapasse os limites do modismo, é preciso investir na transformação da Escola para que ela possa abraçar novas iniciativas, contribuindo assim, para que tais propostas atinjam, de forma significativa, a ponta do processo educativo: os alunos. A novidade precisa ser trazida para dentro da Escola e compreendida por toda a comunidade escolar (VALENTE, 1999, p. 128).

-projetos-arquitetonicos-para-construcao> Acesso em: 9 fev. 2014.
Essa novidade da qual fala o autor já está presente no cotidiano de pelo menos algumas crianças, que se não estão imersas nelas, cada vez mais são expostas ao seu contato.

\section{Considerações Finais}

A Informática na Educação Infantil não tem lugar significativo nos documentos oficiais do Governo Federal, apesar de já ter sido reconhecida como uma oportunidade a ser aproveitada. Neste sentido, o Proinfo poderia incrementar seus investimentos, considerando faixas etárias da educação que, atualmente, não contempla e que pouco a pouco vão demonstrando a importância da prática com computadores por meio de vivências reais. Observar crianças cada vez mais novas em contato com tecnologias dos mais distintos aspectos e formatos é cena comum em nosso cotidiano.

Já o ProInfância poderia voltar-se a ações efetivas de utilização e prática de Informática nas creches e nas pré-escolas, além de pensar em capacitação, mobilização ou desenvolvimento de softwares voltados à esses espaços educacionais e suas devidas faixas etárias. O programa até prevê o desenvolvimento da informática, mas não explica como, quando, onde ou mesmo por quê.

Outra característica da Informática na Educação Infantil nesses documentos é a sua não articulação com todas as outras propostas difundidas. Fala-se do desenvolvimento de habilidades, da escola ser compatível com as transformações pelas quais passa a sociedade, mas nenhuma iniciativa é proposta vinculada à tecnologia ou a Informática propriamente dita.

Já que a Educação Infantil vem consolidando seu espaço como nível de ensino por meio de normativas que asseguram a presença das crianças nesses ambientes educacionais, po- 
dem os documentos oficiais ficar alheios às inovações que já se concretizam ou pelo menos são previstas para os demais níveis de ensino?

O que os documentos indicam é a falta de diretrizes em nosso país para o uso das TICs na Educação Infantil, diferente de outros países. Mesmo sem essas orientações, sabemos que os recursos tecnológicos já são utilizados no Brasil nesses ambientes educacionais, situação que não representa um aspecto positivo, uma vez que essa utilização indiscriminada e sem critérios ou fundamentos pode trazer riscos e colocar em xeque a qualidade da educação oferecida para as crianças. O contexto mostra que atualmente as TICs já fazem parte da Educação Infantil e deverão ganhar mais relevância no futuro.

Apesar dessa reflexão não ter compreendido registros municipais ou estaduais sobre a Informática na Educação Infantil, ela abre caminho para novas problematizações a esse respeito. Como trazer a Informática para dentro das salas de aula dessa primeira etapa da Educação Básica? Para não ter de contentar-se em trabalhar em um ambiente obsoleto e em descompasso com a sociedade atual, como afirma Valente (1999), ações efetivas desde o início são necessárias. Nesse sentido, a Educação Infantil é o ponto de partida.

\section{Referências}

ANDRÉ, C.F. (Org.). Guia de Tecnologias Educacionais 2009. Brasília: MEC/SEB, 2009.

AUBREY, C.; DAHL, S. A review of the evidence on the use of ICT in the early years foundation stage. Coventry, UK: Early Childhood Research Unit Institute of Education; University of Warwick, 2008. Disponível em: <http://dera.ioe.ac.uk/1631/2/becta_2008_eyfsreview_report.pdf> Acesso em: 15 set. 2013.

BRASIL. Constituição (1988). Constituição da República Federativa do Brasil: promulgada em 5 de outubro de 1988. Brasília: Centro gráfico do Senado Federal, 1988.

BRASIL. Projeto de Lei. Aprova o Plano Nacional de Educação para o decênio 2011-2020 e dá outras providências. Brasília, 2010a. Disponível em: <http://www.camara.gov.br/sileg/integras/831421.pdf> Acesso em: 4 ago. 2013.

BRASIL. Ministério da Educação. Secretaria de Educação Básica. Manual de Orientação Pedagógica Brinquedos e Brincadeiras de Creches Brinquedos e Brincadeiras de Creches: manual de orientação pedagógica. Brasília: MEC/SEB, 2012.

BRASIL. Ministério da Educação. Secretaria de Educação Básica. Diretrizes Curriculares Nacionais Para a Educação Infantil. Brasília: MEC/SEB, 2010b. 
BRASIL. Ministério da Educação. Secretaria de Educação Básica. Indicadores de Qualidade na Educação Infantil. Brasília: MEC/SEB, 2009.

BRASIL. Lei n. 12.796, de 4 de abril de 2013. Altera a Lei n 9.394, de 20 de dezembro de 1996, que estabelece as diretrizes e bases da educação nacional, para dispor sobre a formação dos profissionais da educação e dar outras providências. Brasília, 2013. Disponível em: <http://www.planalto.gov.br/ ccivil_03/_Ato2011-2014/2013/Lei/L12796.htm> Acesso em: 15 abril 2013.

BRASIL. Lei n. 9394, de 20 de dezembro de 1996. Estabelece as diretrizes e bases da educação nacional. Brasília, 1996. Disponível em: <http://legis.senado.gov.br/legislacao/ListaPublicacoes. action?id=102480> Acesso em: 17 mar. 2015.

BRASIL. Ministério da Educação e do Desporto. Secretaria de Educação Fundamental. Referencial Nacional Curricular Para a Educação Infantil. Brasília: MEC/SEF, 1998a. V. 1: Introdução.

BRASIL. Ministério da Educação e do Desporto. Secretaria de Educação Fundamental. Referencial Nacional Curricular para a Educação Infantil. Brasília: MEC/SEF, 1998b. V. 3: Conhecimento de mundo.

BUCKINGHAM, David. Beyond Technology: Rethinking learning in the age of digital culture. In: Pettersen, Jan. Perceptions of new literacies, p. 37-43, 2009. Report on the conference Youth Media Democracy. Centre for Social and Educational Research, Dublin Institute of Technology. Disponível em: <http://www.academia.edu/2748420/Beyond_Technology_Rethinking_learning_in_the_age_of_digital_culture>. Acesso em 5 fev. 2014.

Cultura Digital, Educação Midiática e o Lugar da Escolarização. Educação e Realidade, v. 35, no 3, p. 37-58, 2010.

CORDES, C.; MILLER, E. (Ed.). Fool's Gold: A Critical Look at Computers in childhood. New York: Alliance for Childhood, 2000. Disponível em: <http://drupal6.allianceforchildhood.org/fools_gold> Acesso em: 17 nov. 2013.

DAGAN, O.; KUPERMAN, A.; MIODUSER, D. Technological thinking in the kindergarten: training the teaching-team. Tel-Aviv: Tel-Aviv University, School of Education, 2012. Disponível em: <http:// www.ep.liu.se/ecp/073/016/ecp12073016.pdf> Acesso em: 7 nov. 2013.

JANKA, P. Using a Programmable Toy at Preschool Age: why and how? In: INTERNATIONAL CONFERENCE ON SIMULATION, MODELING AND PROGRAMMING FOR AUTONOMOUS ROBOT, 2008, Venice, Italy. Workshop Proceedings of SIMPAR 2008. Venice: [s.n.], 2008. P. 112-121. Disponível em: <http://www.terecop.eu/downloads/simbar2008/pekarova.pdf> Acesso em: 22 out. 2013. 
JESUS, E.A.; URIARTE, M.Z.; RAABE, A.L.A. Zorelha: um objeto de aprendizagem para auxiliar o desenvolvimento musical infantil. Revista Brasileira de Informática na Educação, v. 18, n. 1, p. 91-105, 2010. Disponível em: <http://www.br-ie.org/pub/index.php/rbie/article/view/1212/1109> Acesso em: 21 dez. 2013.

KALAS, I. Recognizing the potential of ICT in early childhood education: analytical survey. MosCOW: UNESCO Institute for Information Technologies in Education, Russian Federation, 2010. Disponível em: <http://iite.unesco.org/pics/publications/en/files/3214673.pdf> Acesso em: 25 ago. 2013.

LIMA, Joelene de Oliveira de. Criando Jogos para a Educação Infantil. Portal de publicações da CEIE - XIII SBIE, 2002. Disponível em: <http://www.br-ie.org/pub/index.php/sbie/article/view/223> Acesso em: 29 jun. 2015.

MATTEI, C. O Prazer de Aprender com a Informática na Educação Infantil. Instituto Catarinense de Pós-Graduação (ICPG). Indaial: 2003. Disponível em: <http://www.educadores.diaadia.pr.gov.br/ arquivos/File/novembro2011/pedagogia_artigos/ainformedinf.pdf> Acesso em: 25 ago. 2013.

MOUSQUER, T.; ROLIM, C.O. A Utilização de Dispositivos Móveis Como Ferramenta Pedagógica Colaborativa na Educação Infantil. Santo Ângelo: URI, 2011. Trabalho apresentado no II Simpósio de Tecnologia da Informação da Região Noroeste do Estado do Rio Grande do Sul, XX Seminário Regional de Informática, Campos de Santo Ângelo da Universidade Regional Integrada do Alto Uruguai e das Missões (URI), 2011. Disponível em: <http://www.santoangelo.uri.br/stin/Stin/trabalhos/11.pdf> Acesso em: 15 out. 2013.

PAPERT, S. A Máquina das Crianças: repensando a escola na era da Informática. Tradução: Sandra Costa. Porto Alegre: Artes Médicas, 1994.

PASSERINO, L.M. Informática na Educação Infantil: perspectivas e possibilidades. In: ROMAN, E.D.; STEYER, V.E. (Org.). A Criança de $\mathbf{0}$ a 6 Anos e a Educação Infantil: um retrato multifacetado. Canoas: ULBRA, 2001. P. 169-180.

PISKE, Joana. Análise de softwares educacionais voltados para educação infantil: levantamento, caracterização e tendências. Núcleo de Estudos e Pesquisa da Educação de 0 a 6 anos (NEE 0 a 6), da Anped, 2000. Disponível em:

<http://23reuniao.anped.org.br/textos/0716p.PDF> Acesso em: 29 jun. 2015.

ROSA, C.P. O Computador Como Ferramenta Pedagógica na Educação Infantil. [S.I.: S.n.], 2010. Trabalho apresentado no Congresso Norte-Nordeste de Pesquisa e Inovação (CONNEPI), Maceió, 2010. Disponível em: <http://connepi.ifal.edu.br/ocs/index.php/connepi/CONNEPI2010/paper/viewFile/1018/769> Acesso em: 11 out. 2013. 
SCHLICKMANN, V. et. al. Informática na Educação Infantil. Revista Educação em Rede, Florianópolis, v. 1, n. 1, nov. 2006. Disponível em: <http://www.revistas.udesc.br/index.php/educacaoemrede/ article/view/1750/1372> Acesso em: 11 out. 2014.

SIRAJ-BLATCHFORD, I.; SIRAJ-BLATCHFORD, J. A guide to developing the ICT curriculum for early childhood education. London: Cromwell Press, 2006.

TAVARES, Tatiana Aires et. al. A TV Digital interativa como ferramenta de apoio à Educação Infantil. Portal de publicações da CEIE - Revista Brasileira de Informática na Educação, v. 15, n. 2, 2007. Disponível em: <http://www.br-ie.org/pub/index.php/rbie/article/view/65/54> Acesso em: 29 jun. 2015.

VALENTE, J.A. Diferentes Usos do Computador na Educação. In: VALENTE, J.A. (Org.). Computadores e Conhecimento: repensando a educação. Campinas: NIED/UNICAMP, 1993, p. 1-28.

VALENTE, J.A. Informática na Educação: instrucionismo x construcionismo. Revista Educação Pública, Rio de Janeiro, [1997]. Disponível em: <http://www.educacaopublica.rj.gov.br/biblioteca/tecnologia/0003.html> Acesso em: 11 set. 2013.

VALENTE, J.A. O Computador na Sociedade do Conhecimento. Campinas, SP: UNICAMP/ NIED, 1999.

VILLARDI, R.; OLIVEIRA, E.G. Tecnologia na Educação: uma perspectiva sócio-interacionista. Rio de Janeiro: Dunya, 2005. 